\title{
Fracturing Truss Model: Size Effect in Shear Failure of REINFORCED CONCRETE
}

\author{
By Zdeněk P. Bažant, ${ }^{1}$ Fellow, ASCE
}

\begin{abstract}
The classical truss model (or strut-and-tie model) for shear failure of reinforced concrete beams is modified to describe fracture phenomena during failure. The failure is assumed to be caused by propagation of a compression fracture across the concrete strut during the portion of the loading history in which the maximum load is reached. The compression fracture may consist of a band of splitting cracks that later interconnect to form a shear crack or a shear fracture band inclined to the strut. The width of the fracture band is assumed to occupy only a portion of the strut length and to represent a fixed material property independent of the beam depth. The energy release from the truss is calculated using two alternative approximate methods: (1) using the potential energy change deduced from the concept of stress relief zones; and (2) using the complementary energy change due to stress redistribution caused by propagation of the fracture band across the compressed concrete strut. Both approaches show that a size effect on the nominal strength of shear failure must exist and that it should approximately follow the size effect law proposed by Bažant in 1984. The physical mechanism of the size effect is also explained in a clear and simple intuitive manner. Finally, it is shown that the applied nominal shear stress that causes large initial diagonal cracks to form also exhibits a size effect.
\end{abstract}

\section{INTRODUCTION}

Although much has been learned about the shear failure of reinforced concrete beams during this century, the physical mechanism is still not adequately understood. The shear failure in a quasi-brittle material such as concrete involves progressive evolution of distributed damage and its localization into fracture, which causes a size effect. This is a major problem of the mechanics of solids today. It is a problem of great difficulty, in which simplified mathematical formulations are at this time inevitable.

The classical approaches to shear design of reinforced concrete beams are of two types: (1) empirical equations based on the concept of strength, which have been used for a long time in the ACI Code 318 (Building 1985) as well as other codes [CEB-FIP 1990 (Model 1993), Eurocode EC2, 1991 (Design 1991)]; or (2) formulations based on the lower bound theorem of the theory of plasticity. These approaches exhibit no size effect, i.e., the nominal strength of the beam at failure is predicted as independent of the beam size when geometrically similar beams are considered.

In the literature, there exist over 470 experimental studies of the shear failure of reinforced concrete beams. Among them, there exist only 10 studies, most of them recent, that include the beam size as a variable parameter and provide a direct evidence of size effect; see Leonhardt and Walter (1962a,b), Rüsch (1962), Kani (1967), Bahl (1968), Taylor (1972), Walraven (1978, 1981), Chana (1981), Iguro et al. (1985) [also Shioya et al. (1989); Shioya and Akiayama (1994)], Bažant and Kazemi (1991), Khorasgany (1994), and Walraven and Lehwalter (1994). Furthermore, there are very recent large-size test data by Gopalaratnam at University of Missouri, Columbia, orally presented at the ACI Convention in Denver in 1996.

Kani's (1967) study was the first that provided unequivocal evidence of a strong size effect. All the test data available in the literature in the mid 1980s, which included several hundred test series, were statistically analyzed for the evidence of size

\footnotetext{
'Walter P. Murphy Professor of Civil Engineering and Materials Science, Northwestern Univ., Evanston, IL 60208.

Note. Associate Editor: Robert Y. Liang. Discussion open until May 1, 1998. To extend the closing date one month, a written request must be filed with the ASCE Manager of Journals. The manuscript for this paper was submitted for review and possible publication on October 15 , 1996. This paper is part of the Journal of Engineering Mechanics, Vol. 123, No. 12, December 1997. OASCE, ISSN 0733-9399/97/0012-1276$1288 / \$ 4.00+\$ .50$ per page. Paper No. 13276 .
}

effect by Bažant and $\operatorname{Kim}(1984,1985)$, Bažant and Sun (1987) and Bažant and Cao (1986). Because test data for one beam size from one laboratory had to be compared to test data for another beam size from another laboratory, and because most studies varied simultaneously several parameters and did not adhere to geometrical scaling, it came as no surprise that the scatter was very high. Nevertheless, a size effect was clearly discernible. With the recent data, the existence of a strong size effect [e.g., Mihashi et al. (1994), Bažant et al. (1994)] is now clear and has become widely accepted, contrary to the situation a decade ago. The problem is how to explain it and model it.

To explain the size effect, three theories have been proposed: (1) a Weibull-type theory of random strength; (2) the theory of fracture energy release [based on Bazant (1983, 1984)]; and (3) the theory of fractal character of crack surfaces or microcrack distributions (Carpinteri et al. 1994, 1995a,b).

Weibull's theory (1939) [which underlies the power law used in the Japanese code for shear failure of beams (Design 1986; Standard 1991; Okamura and Maekawa 1994)] is the classical explanation of size effect. But it applies only to structures that fail at the initiation of macroscopic fracture from a microscopic flaw, for example, brittle metallic structures. This theory has been shown (Bažant et al. 1991; Bažant and Xi 1991) to be inapplicable to structures that fail after large stable growth of damage or fracture, which is the case for concrete. The fractal theory is not viable because it was shown that the mathematical consequences disagree with the experimental evidence, and the fractal hypothesis does not match the known physical mechanism (Bažant 1995a,b, 1996, 1997). That leaves the energy release theory.

There are several clues indicating that the energy release theory ought to apply. It is now well understood that whenever the load-deflection diagram of a structure exhibits postpeak softening (Fig. 1) and the softening is not caused by overall buckling of the structure, damage localization must be taking

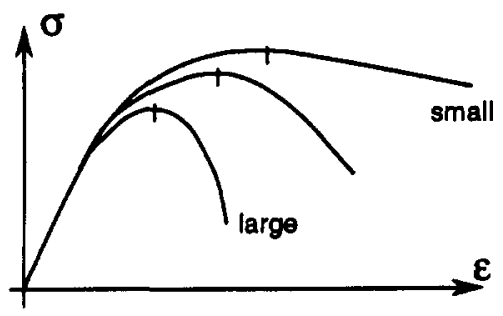

FIG. 1. Dependence of Effective Stress-Strain Diagram of Compression Strut on Beam Size 
place and must cause a size effect. As shown by dimensional analysis and the theory of similitude, when the criterion of failure of a material is expressed solely in terms of a critical stress or critical strain, no size effect can exist, but when the material failure criterion is expressed in terms of energy, as in fracture mechanics, the size effect must occur (Bažant 1994). An asymptotic analysis of the general failure conditions according to quasi-brittle fracture mechanics independently again shows that a size effect must exist, and application of the technique of asymptotic matching yields a formula for the size effect (Bažant 1995a,b, 1996, 1997a). The nonlocal finite element models and nonlinear fracture mechanics provide further support (Bažant et al. 1994).

For the diagonal shear failure in particular, a fourth type of explanation was proposed by Reineck (1991), Collins and Mitchell (1991), and Collins et al. (1996). The hypothesis was that (1) the width of the major cracks at failure is approximately proportional to the beam depth (size); (2) the failure load depends on the transfer of shear stress across the cracks due to friction and aggregate interlock; and (3) the increase of crack opening reduces the shear stress transfer capability. Of course, whenever there is any dependence of the stress on the displacement (rather than the strain), in this case the crack opening, a size effect is engendered. However, there are four arguments indicating that the foregoing hypothesis cannot explain the main source of the observed size effect:

1. The crack width is not proportional to the beam depth and is governed mainly by the spacing and size of reinforcing bars (Hsu and Zheng 1996).

2. The main cracks at the moment of failure run predominantly in the direction of the compressive principal stress, which is the essential assumption of the truss model or strut-and-tie model [e.g., Schlaich et al. (1987)], and so the major cracks (Fig. 2) transmit no significant shear stresses that would matter. (Considering transmission of significant shear and normal stresses across the diagonal cracks would be tantamount to rejecting the truss model, or strut-and-tie model.)

3. The opening of the diagonal shear crack at failure of a simply supported beam is the widest at the bottom of the beam while the failure of the material occurs in the compression zone near the top of the beam.

4. The crack opening width, anyway, does not control the maximum load (it controls the cracking load), and consequently, because a widely opened diagonal crack forms before the maximum load, the opening width of this crack must be relevant to the cracking load rather than the failure load.

Applying the condition of energy balance, Bažant and Kim (1984) introduced the size effect law as a correction of a strength-based formula for the nominal shear strength and showed that it allows a distinctly better statistical agreement with the existing test results. This study was extended by Bažant and Sun (1987). For prestressed concrete and for punching of slabs, it is further extended by Bažant and Cao (1986, 1987). However, a simple, intuitively clear physical explanation of the mechanism of size effect in shear failure has not been given. To offer such an explanation is the objective of the present study. However, the objective is not to propose definitive design formulas and procedures. This will require extensive comparisons with the existing test data and with other design formulas. The goal of the present study is to elucidate in the simplest possible manner the physical mechanism of size effect by using fracture mechanics. Fracture mechanics is a theory in which it is recognized that, if the strength limit of the material has been attained, a break of the material will
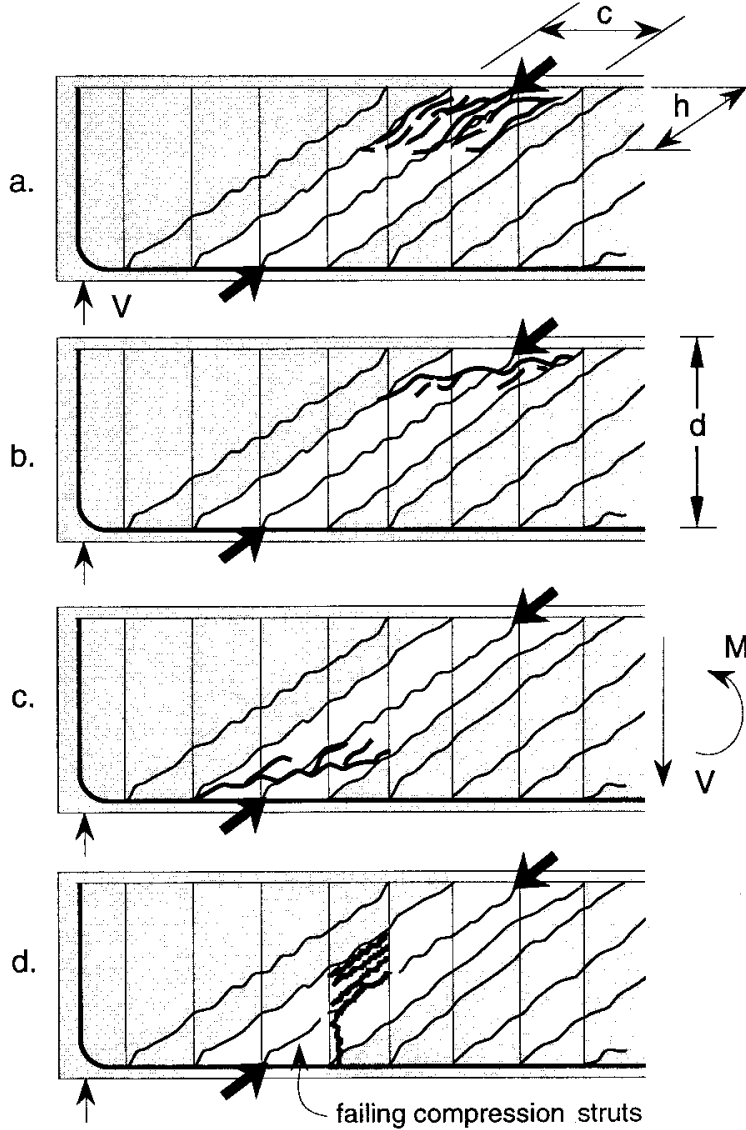

(stress relief, energy release)

FIG. 2. Various Types of Localized Fracture of Compression Struts and Stress Relief Zones (Unshaded)

occur if and only if the structure-load system can supply the energy required to cause the break.

The analysis that follows exploits the classical truss model, which was proposed by Ritter (1899) and Mörsch in 1902 (Mörsch 1922) and was experimentally further verified by Whithey (1907, 1908), Talbot (1909), and others. In this model, approximately straight and parallel cracks are assumed to form in the direction of the compressive principal stress before the maximum load is reached (Fig. 2). As is now well understood, the principal tensile stress does not get reduced to zero, since the cracks are cohesive cracks capable of transmitting crack-bridging tensile stresses. However, the crackbridging stresses are certain to be much smaller than the tensile strength of concrete, while the magnitude of the compressive stresses in the compressed struts of concrete between the parallel cracks must be at or near the compression strength limit, which is about 10 times higher than the tensile strength. It follows that the crack-bridging stresses, while nonzero, must be negligible in comparison to the compressive stresses. This fact justifies the truss model, recently often called the strutand-tie model.

This simple but powerful model was improved by introduction of rational criteria for determining the angle of the dominant diagonal cracks. These criteria were based first on energy minimization (Kupfer 1964) and later on Mitchell and Collins's (1981) adaptation of Wagner's (1929) condition (for web buckling in steel girders) stating that the average strains in the stirrups, longitudinal steel bars, and diagonal compressions struts must be compatible [this was called the compression field theory; see also Collins (1978) and Vecchio and Collins (1986)]. Another version of the truss model extending Kani's concept of shear transmitting teeth was presented by Reineck (1991). 
Thürlimann (1976) and Nielssen and Braestrup (1975) presented a strict plasticity formulation of the truss model based on the normality rule, yield surfaces exhibiting slip with dilatancy, and the lower bound theorem of the theory of plasticity [see also Marti $(1980,1985 a, b)]$. Concrete, however, is not a plastic material. The plastic limit analysis does not apply to concrete, since concrete exhibits strain softening, which is a phenomenon describable only by the energetic failure concept of fracture mechanics. Therefore, the plastic limit analysis cannot capture the effect of structure size. This classical approach implies the failure to occur simultaneously along the entire failure surface (as a single-degree-of-freedom mechanism), which is a basic (but usually unstated) hypothesis of plastic limit analysis. In reality, the failure occurs progressively, the more so the larger the structure. This calls for a fracture mechanics approach.

In particular, a diagonal compression strut cannot fail simultaneously along the entire length and width. Instead, it fails by progressive fracture of concrete within a certain critical zone occupying only a portion of the length and width of the strut. How large a portion depends on the beam size. Furthermore, the crushed zone propagates across the strut while the rest of the strut is getting unloaded, releasing its energy and thus driving the failure. Hence, the apparent compression strength of the strut cannot be constant but must decrease with an increasing length of the strut (or the beam depth).

Fortunately, however, the truss model need not be discarded. It suffices to modify it by introducing the energetic concept of fracture mechanics. How to do this in a simple manner is the idea of the approximate analysis that follows. This analysis avoids a rigorous solution of the nonlinear boundary value problem, which can be accomplished only numerically, e.g., by finite elements. Such a "brute-force" numerical solution is appropriate for checking a design but can provide neither insight into the failure mechanism nor simple formulas suitable for design.

\section{BASIC DEFINITIONS AND HYPOTHESES}

The size effect represents the size dependence of the nominal shear strength of a beam, which is defined as

$$
v_{u}=V_{u} / b d
$$

where $V_{u}=$ value of the applied shear force $V$ at the ultimate (maximum) load; $d=$ depth of the longitudinal reinforcement below the top face of the beam (Figs. 2 and 3); and $b=$ width of the rectangular cross section of the beam. For the sake of simplicity, the beam is considered to have a rectangular cross section, although a generalization to flanged cross sections would not be difficult. To separate the size effect from other effects, one must compare beams of different sizes that are geometrically similar.

The shear span $a$ is defined in Fig. 3(b) for a simply supported beam with two symmetric concentrated loads. When a uniform load is present, the shear span may be defined as $a=$ $M / V$, where $M$ is the bending moment in the critical cross section, leaving the analysis that follows unchanged.

Hypothesis I. The truss model, which simplifies the problem by making the stresses statically determinate and easy to calculate, is assumed to be a valid approximation.

If the truss model is valid, the failure can occur only by ductile failure (i.e., yielding) of the steel ties or longitudinal bars, or by brittle failure of the compression struts. The former type of failure is well understood, and we are interested only in the latter. Assuming the compression struts to be straight is a simplification (if the shear force $V$ varies, it would be more accurate, but more complicated, to consider a compression arch).

If a yield or strength criterion were applicable, the concrete

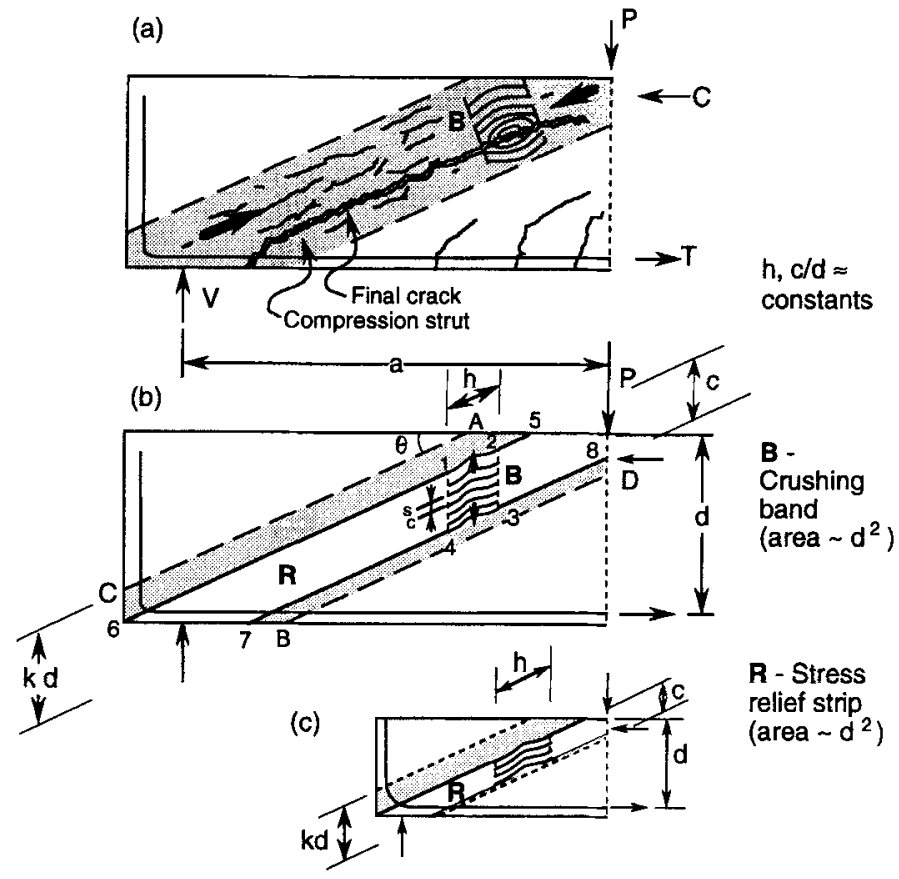

FIG. 3. (a) Compression Strut in Beam without Stirrups and Fracture Zone Propagating across Compression Strut during Failure; (b) Stress Relief Zones Caused by Fracture Band Propagating across Compression Strut in Beams of Different Sizes

would fail simultaneously everywhere in the strut. However, because concrete is brittle and exhibits postpeak strain softening in compression, the failure of concrete must localize into a fracture zone. The size of this localized zone is independent of the beam size and is decided mainly by the size and spacing of material heterogeneities (especially the large aggregate pieces) and by the value of Irwin's characteristic length of the material, $l=E G_{f} /\left(f_{t}^{\prime}\right)^{2}$ (introduced for concrete by Hillerborg), where $E=$ Young's modulus, $G_{f}=$ fracture energy, and $f_{t}^{\prime}=$ tensile strength. So, the following, essential, hypothesis is reasonable.

Hypothesis II. The compression strut fails only within a portion of its area, and the depth of the localized failure zone is independent of the beam size (Fig. 2).

Hypothesis III. The failure modes (or failure surfaces) at maximum load of beams of different sizes are geometrically similar.

Hypothesis III means that, for example, the shear span $a$ [Fig. 3(b)] and the length $c$ of the material failure zone or fracture zone at maximum load are geometrically similar. In other words, the ratios a/d and (for large enough sizes) $c / d$ are assumed to be constant. This hypothesis is of course applicable only within a certain range of sizes. However, experience from testing as well as finite element analysis indicates that this range covers the size range of practical interest.

The localized failure of compression strut, postulated in hypothesis II, may occur in various ways (Fig. 2). Most likely, the failure zone at maximum load consists of a band of splitting cracks in the strut direction, propagating laterally (Bažant and Xiang 1996), which is what is considered in the following. This band may be located anywhere along the strut length [Figs. 2(a,c,d)]. The location of this band within the strut is immaterial for the analysis that follows, although we will picture the location on top [Fig. 2(a)], which seems most likely. In postpeak deflection, the splitting cracks either interconnect and produce a failure that looks like a shear failure [Figs. $2(b-d)]$, although the failure did not start by shear, or they lead to onset of compression crushing of concrete [at the end of the test; however, after the load has been reduced to zero, 
compression crushing is observed only in T-beams; Leonhardt (1977)]. Alternatively, a propagating shear fracture, inclined with respect to the strut [Figs. 2(b,c)], may already exist.at the maximum load. Which of these detailed fracture modes takes place is immaterial for the simplified analysis based on the truss model. They all lead to mathematically equivalent results.

Denying that at maximum load the concrete is fracturing due to compression in the struts would be tantamount to denying the validity of the truss model (strut-and-tie model) itself. If this model is valid, then (1) diagonal tensile cracks must form before the maximum load; (2) only negligible tensile and shear stresses can exist on the planes of these cracks; and (3) the compression struts between these cracks must be aligned in the direction of the compressive principal stress in concrete. Only under these conditions can the concrete, stirrups, and longitudinal bars be treated as a truss.

The energy release due to fracture propagation can be calculated in two ways: (1) from the change of the potential energy of the structure-load system at constant displacement; or (2) from the change of the complementary energy of the structure at constant load [see, e.g., Bažant and Cedolin (1991)]. We will examine both approaches in a simplified manner and show that they give approximately the same results.

\section{ANALYSIS BASED ON STRESS RELIEF ZONE AND POTENTIAL ENERGY}

\section{Longitudinally Reinforced Concrete Beam without Stirrups}

The typical pattern of cracks forming during the failure of a simply supported beam is seen in Fig. 3(a) (which shows the left-end portion of the beam only). Although, after the failure, only one final diagonal crack emerges, cracks of various orientations form during the loading process. The first cracks caused by shear loading are tensile cracks of inclinations of approximately $45^{\circ}$. On approach to the maximum load, these cracks interconnect and form a larger crack running approximately along the line connecting the application points of the load $P$ and the reaction $V$ in Fig. 3(a). This major crack is free of shear stresses and has approximately the direction of the maximum principal compression stress $\sigma_{n 1}$.

According to the truss model (or strut-and-tie model), we may imagine that most of the load is transferred through the shaded zone called the compression strut (in the case of distributed load it would be more accurate to consider a compressed arch). The normal stress in the direction orthogonal to the strut is essentially zero, and the material can expand freely in that direction.

The failure behavior is approximately idealized as shown in Fig. 3(b) for two geometrically similar beams of different sizes. Although for calculation purposes the compression strut is assumed to represent a one-dimensional bar connecting the points of application of $P$ and $V$, it has a finite effective width, denoted as $k d$ [Fig. 3(b)], where $d$ is the depth to the reinforcement and $k$ is approximately a constant, independent of the beam size.

As suggested by some experimental observations and supported by finite-element results, the progression of failure at maximum load is caused by onset of compression failure of the concrete near the upper end of the compression strut, provided that the longitudinal bar is anchored sufficiently so that it cannot slip against concrete near the beam support. Aside from the fact that the compression fracture occurs only within a portion of the length of the strut, the basic premise of the present analysis is that the width $h$ of the fracture zone in the direction of the strut is, for a given concrete, approximately a constant (which is probably approximately proportional to the maximum aggregate size and also depends on other material characteristics).

The fact that $h$, in contrast to the length and width of the stress-relieved strip in the strut [the white strip 56785 in Figs. $3(\mathrm{~b}, \mathrm{c})$ ], is not proportional to the beam size is the cause of the size effect. If and only if the depth $h$ of the fracture band were proportional to the beam size, there would be no size effect. For calculation purposes, we will assume that the compression failure of the material consists of a fracture band 12341 [Fig. 3(b)] growing vertically across the strut upward or downward, or both (which of these, is immaterial for the present analysis).

Microscopically, the compression fracture may be regarded as internal buckling of an orthotropically damaged material (Bažant and Xiang 1996). The fracture process begins by formation of dense axial splitting microcracks in the direction of maximum compression, which reduces the transverse stiffness of the material, thus causing the microslabs of the material between the microcracks to buckle laterally. This idea, which is an adaptation to damaging materials of the idea proposed by Biot (1965) for elastic materials, has recently been pursued in detail elsewhere (Bažant and Xiang 1996). However, these details are not needed for the present analysis. Neither is it important that the fracture band is pictured propagating vertically. If it propagated across the strut in an inclined or horizontal direction, the calculation results would be equivalent.

The growth of the fracture band, which causes the loaddeflection curve to reach a maximum load and subsequently decline, relieves the compression stress from strip 56785 shown in Fig. 3(b). The reason that the boundaries of the stress relief zone, that is, the lines $16,25,38$, and 47 , are parallel to the direction of the strut is that the material is heavily weakened by cracks parallel to the strut. Otherwise a more realistic assumption would be a triangular shape of the stress relief zone, as considered in the case of tensile failures (Bažant 1984; Bažant and Cedolin 1991, chapter 13); see the explanation in Appendix I.

Now, how to make the size effect intuitively clear with minimum calculations? To this end, note that the area of stress relief zone 56785 in Fig. 3(b) is proportional to $c a$, where $c$ is the length of the fracture band at failure. Since $c a=$ $(c / d)(a / d) d^{2}$, and $c / d$ and $a / d$ are constants independent of $\bar{d}$, the area of stress relief zone is proportional to $d^{2}$. Because the average strain energy density in the strut is proportional to the nominal shear stress at ultimate load $v_{u}^{2}$, the total energy release from the stress-relieved strip 56785 of the strut is proportional to $v_{u}^{2} d^{2}$. However, assuming that the energy dissipation per unit volume of the fracture band is constant, the energy dissipation in the entire fracture band is proportional to $d$, because the area of the fracture band is proportional to $c h=(c / d) h d$. Therefore, varying the beam size $d, v_{u}^{2} d^{2}$ must be proportional to $d$, which means that $v_{\mu}$ must be proportional to $1 / \sqrt{d}$. This represents a size effect, in fact a very strong size effect (corresponding to linear elastic fracture mechanics).

In summary, the cause of the size effect is simply the fact that the energy release from the structure is approximately proportional to $v_{u}^{2} d^{2}$, whereas the energy consumed by fracture is approximately proportional to $d$.

Let us now do the calculations in detail. The condition that the entire shear force $P$ must be transmitted by the compression strut yields for the axial compression stress in the strut the following expression:

$$
\sigma_{c}=\frac{1}{b k d} \frac{V}{\sin \theta \cos \theta}=\frac{v_{u}}{k}\left(\frac{a}{d}+\frac{d}{a}\right)
$$

where $\theta=$ inclination angle of the compression strut from the horizontal (note that $\tan \theta=d / a$ ). The strain energy density in the strut is $\sigma_{c}^{2} / 2 E_{c}$, where $E_{c}=$ Young's modulus of concrete. The volume of the strut is $a b c$ (where $b=$ beam width). There- 
fore, the loss of potential energy from the beam caused by stress relief during the formation of compression fracture band at constant load-point displacement is, approximately:

$$
\Pi_{c}=-\frac{\sigma_{c}^{2}}{2 E_{c}} a b c=-\frac{v_{u}^{2}}{2 E_{c} k^{2}}\left(\frac{a}{d}+\frac{d}{a}\right)^{2} a b c
$$

The minus sign expresses the fact that this is an energy loss rather than gain. According to the principles of fracture mechanics [see, e.g., Bažant and Cedolin (1991), section 12.1], the energy release rate due to the growth of the fracture band is obtained as

$$
\mathscr{G}=-\left[\frac{\partial \Pi_{c}}{\partial c}\right]_{\mu}=\frac{v_{u}^{2} a b}{2 E_{c} k^{2}}\left(\frac{a}{d}+\frac{d}{a}\right)^{2}
$$

The energy dissipated by the fracture band may be expressed on the basis of the fracture energy $G_{f}$ characterizing the axial splitting microcracks in the fracture band. The length of these cracks is $h$ (width of the band), and their average spacing is denoted as $s_{c}$. The number of axial splitting cracks in the band is $c / s_{c}$. Thus the total energy dissipated by the fracture band is $W_{f}=\left(c / s_{c}\right) b h G_{f}$. Differentiating with respect to $c$, we find that the energy dissipation in the fracture band per unit length of the band, $\mathscr{R}$, is

$$
\mathscr{R}=\frac{b h}{s_{c}} G_{f}
$$

In this equation, however, it would be too simplistic to consider $h$ as constant through the entire evolution of the compression fracture band. Naturally, the fracture band must initiate from a small zone of axial splitting cracks. The length of these cracks first extends in the direction of the strut until they reach a certain characteristic length $h_{0}$. Only then does the fracture band grow across the strut at roughly constant width $h=h_{0}$ [see the intuitive picture of the subsequent contours of the fracture zone in Fig. 3(a)]. Such behavior may be simply described by the equation

$$
h=h_{0} \frac{c}{w_{0}+c}
$$

where $h_{0}, w_{0}=$ positive constants, $h_{0}$ representing the final width of the fracture band. Thus, strictly speaking, our hypothesis of a constant width of the fracture band (hypothesis II) means that the final width $h_{0}$ rather than $h$ is a constant. Constant $w_{0}$ will surely have different values for different concretes (e.g., it will probably increase with the maximum aggregate size $d_{a}$ and with Irwin's characteristic length $l=$ $E G_{f} / f_{i}^{\prime 2}$, which necessitates further study).

The increase of $\mathscr{R}$ with $c$, as described by (5) with (6), represents what is called the $R$-curve behavior [because $\mathscr{R}$ represents the resistance to fracture; see, e.g., Bažant and Cedolin (1991), Bažant and Planas (1997)]. The $R$-curve behavior in tensile fracture is also caused by the growth of the fracture process zone size. Here, however, this growth is expressed indirectly in terms of the length of the axial splitting cracks in the fracture band.

If, alternatively, the peaking of the load is caused by propagation of a shear crack of the kind shown in Fig. 2(b), one should introduce the fracture energy of the compression-shear crack $\Gamma_{f}$ and write the critical energy required for crack growth as

$$
R=\Gamma_{f} b \frac{c}{w_{0}+c}
$$

But this is equivalent to (5) with (6) if one sets $\Gamma_{f}=G_{f} h_{0} / s_{c}$. So, from now on we will consider that the peaking of the load is due to propagation of a band of splitting cracks, and the

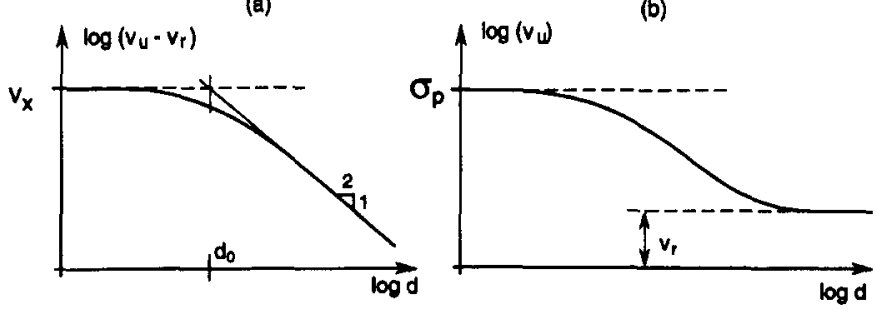

FIG. 4. Size Effect in Shear Fallure of Concrete Beam in Terms of Logarithm of Either $v_{u}$ or $v_{u}-v_{r}$

solution for the case of peaking due to compression shear fracture will be automatically obtained by replacing $h_{0} / s_{c}$ with $\Gamma_{f} / G_{f}$.

The balance of energy during equilibrium propagation of the fracture band requires that

$$
\mathscr{G}=\mathscr{R}
$$

Substituting here the expressions in (4)-(6), one obtains the result

$$
v_{u}=v_{p}\left(1+\frac{d}{d_{0}}\right)^{-\mathrm{t} / 2}
$$

in which the following notations have been made

$$
\begin{aligned}
& d_{0}=w_{0} \frac{d}{c} ; \quad v_{p}=c_{p} K_{c}\left(\frac{a}{d}+\frac{d}{a}\right)^{-1} \\
& K_{c}=\sqrt{E_{c} G_{f}} ; \quad c_{p}=k \sqrt{\frac{2 h_{0}}{w_{0} s_{c}} \frac{c / d}{a / d}}
\end{aligned}
$$

Here the expression for $K_{c}$ is that for the fracture toughness (the critical stress intensity factor) of the axial splitting microcracks. An important point is that, because of our assumptions (constant $c / d, a / d$ ), the values of $d_{0}, v_{p}$, and $c_{p}$ are constant, independent of size $d$. The value $v_{p}$ is the limiting (asymptotic) value of the nominal shear strength for very small size $d$.

Eq. (9) represents the size effect law proposed by Bažant $(1983,1984)$. This law was introduced into the analysis of diagonal shear failure by Bažant and Kim $(1984,1985)$, however, on the basis of a more general and less transparent argument.

By the same calculation procedure, it can also be easily shown that if, contrary to hypothesis II, the width $h$ of the fracture band were proportional to $d$ instead of obeying (6), there would be no size effect. But if $h$ would vary with $d$ other than proportionally, there would always be a size effect.

If the constant $w_{0}$ were taken as 0 , one would have $v_{p} \propto$ $d^{-1 / 2}$, which is the size effect of linear elastic fracture mechanics (LEFM), representing the strongest size effect possible. However, most experimental data exhibit a weaker size effect, which implies that the constant $w_{0}$ should be considered finite.

The plot of the size effect curve given by (9) is shown in Fig. 4(a). This curve represents a smooth transition from a horizontal asymptote corresponding to the strength theory or plastic limit analysis to an inclined asymptote of slope $-1 / 2$, corresponding to LEFM. The approach to the horizontal asymptote means that the plasticity approach, that is, the truss model, can be used only for sufficiently small beam sizes $d$.

For very small beam sizes $d$, we may substitute in (2) $\sigma_{c}=f_{c}^{b}=$ compression strength of the strut, and replace $v_{u}$ by plastic nominal strength $v_{p}$. From this we can solve

$$
v_{p}=k f_{c}^{b}\left(\frac{a}{d}+\frac{d}{a}\right)^{-1}
$$

which is equivalent to (10). Thus, the size effect law in (9) can be alternatively written as 


$$
v_{u}=k f_{c}^{b}\left(\frac{a}{d}+\frac{d}{a}\right)^{-1}\left(1+\frac{d}{d_{0}}\right)^{-1 / 2}
$$

which shows also the effect of the relative shear span ald on the nominal shear strength. Note that $f_{c}^{b}$ cannot be expected to represent the uniaxial compression strength $f_{c}^{\prime}$ of concrete, since the progressively fracturing concrete in the strut is under high transverse tensile strain in the other diagonal direction and has been orthotropically damaged by cracking due to previous high transverse tensile stress (Hsu 1988, 1993). So $f_{c}^{b}$ is a certain biaxial strength of concrete, depending both on the uniaxial compression strength $f_{c}^{\prime}$ and the direct tensile strength $f_{i}^{\prime}$. This dependence needs to be calibrated by shear tests of beams.

It is interesting to determine the ratio to the nominal strength for bending failure $\sigma_{N}^{b}$. The ultimate bending moment in the cross section under the load $P$ is $M_{u}=V a=\sigma_{N}^{b} b a d$. From the moment equilibrium condition of the cross section under the load $P$ we also have $M_{u}=\left(f_{y} \rho b d\right) k_{b} d$, in which $f_{y}$ is the yield strength of the longitudinal reinforcing bars, $\rho$ is the reinforcement ratio (which means that $\rho b d$ is the cross section area of the longitudinal reinforcing bars), and $k_{b} d$ represents the arm of the internal force couple at the ultimate load. As is well known, $k_{b}$ is approximately constant. Equating the expressions for $M_{u}$, we obtain $\sigma_{N}^{b}=\rho f_{y} k_{b} d / a$. Considering now (13), we conclude that

$$
\frac{\sigma_{N}^{b}}{v_{u}}=\frac{\rho f_{y} k_{b}}{k f_{c}^{b}}\left(1+\frac{d^{2}}{a^{2}}\right) \sqrt{1+\frac{d}{d_{0}}}
$$

This equation shown that the ratio of the nominal bending strength to the nominal shear strength of the beam decreases when the relative shear span ald increases, which confirms a well-known fact. It means that slender beams, for which ald is large, fail by bending, while deep beams, for which a/d is small, fail by shear. However, as is clear from (14), the relative shear span a/d at the transition between the shear and bending failures is not constant but is larger for a larger beam size $d$. To express it precisely, we set

$$
\sigma_{N}^{b}=v_{u}
$$

in (14). This furnishes a cubic equation for the transitional shear span ald, which will obviously exhibit a size effect.

There is a question whether the progressive fracturing of concrete reduces the compression stress all the way to zero. It could be that the compression stress $\sigma_{c}$ is reduced to some small but finite residual strength $\sigma_{r}$. However, this seems realistic only when we consider beams with stirrups, which provide some degree of confinement. Without confinement, a finite residual strength might not exist. If $\sigma_{r}$ were nonzero for the present case, it would have the effect of adding a constant term to the right-hand side of (9).

The tensile strength of concrete $f_{t}^{\prime}$ has played no direct role in the foregoing analysis. The tensile strength is not a material parameter in LEFM, nor in the $R$-curve model of nonlinear fracture. It does appear in the cohesive (fictitious) crack model or the crack band model. However, those models are too complicated for achieving a simple analytical solution. The tensile
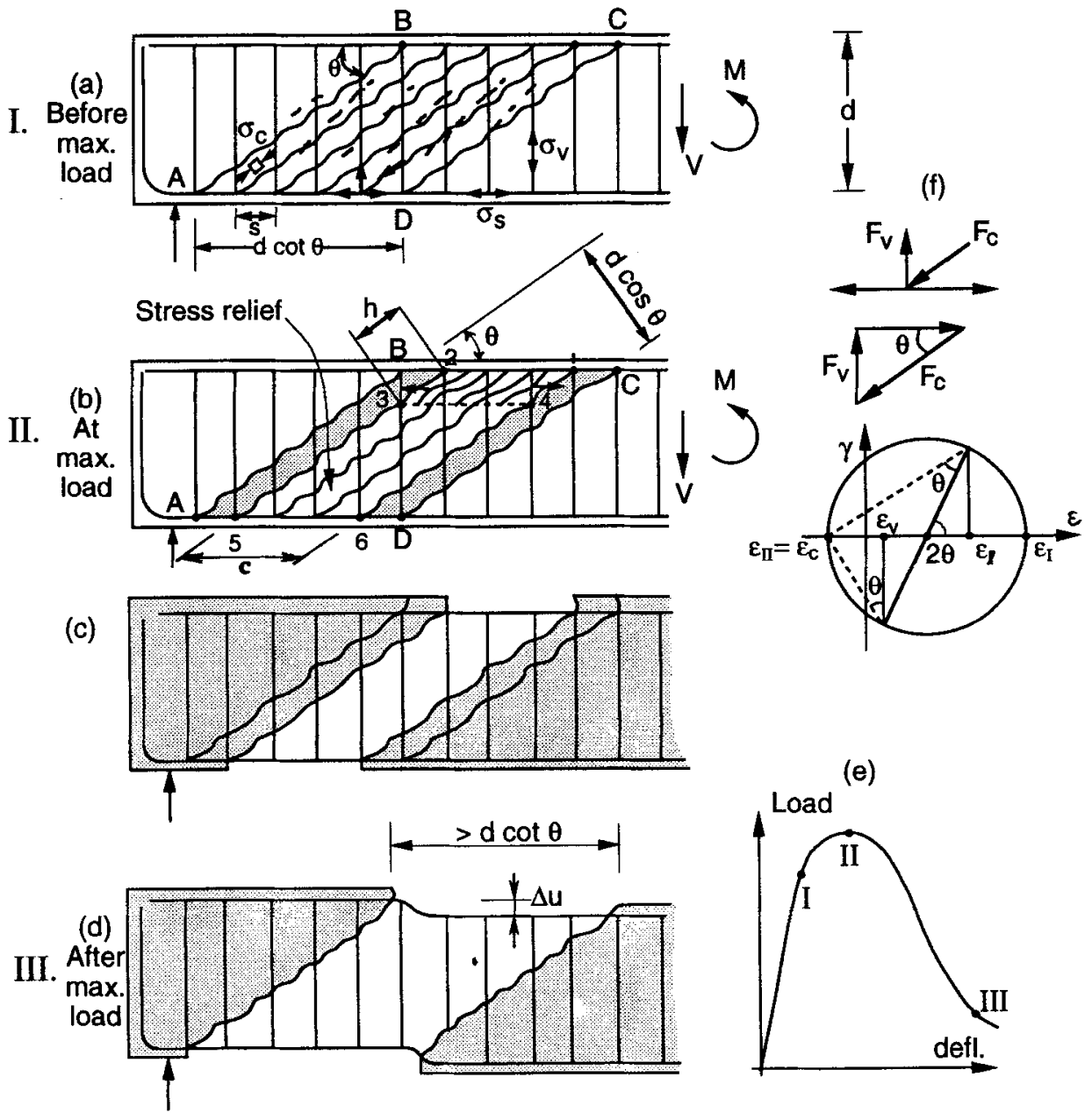

FIG. 5. Evolution of Diagonal Cracks in Beam with Stirrups under Shear Loading: (a) Diagonal Crack Formation before Maximum Load; (b) Growth of Fracture Band Across Compression Strut during Failure at Maximum Load; (c) Beam at Maximum Load with Crushed and Stress-Relieved Part of Compression Strut Removed; (d) State of Beam without Crushed and Stress-Relieved Concrete after Collapse (I.e., Load Has Been Reduced to Small Value); and (e) Equilibrium of Forces in Stirrups and Struts 
strength, of course, controls the initiation of the inclined shear cracks; however, their growth is governed by fracture energy. In the present analysis we take the view that the inclined cracks due to shear loading have already formed before the maximum load and thus no longer grow during failure.

Does shear stress transmission across cracks due to friction and aggregate interlock play any role? It could, although according to the present analysis it cannot be significant. As shown in Fig. 3(a), only cracks rather curved within the area of the compression strut can be subjected to shear and normal loading. Their capability of shear stress transmission decreases with the crack width, and the crack width may be assumed to increase with an increasing beam size, which obviously would also introduce a size effect [this idea was proposed by Reineck (1991)]. The cracks are the most inclined to the compression strut direction and are opened the most widely at the bottom of the beam. However, the maximum load appears to be controlled by progression of compression fracture near the major crack at the top of the beam. For this reason, the effect of crack opening on the shear stress transmission across cracks can hardly play a major role in the size effect on the maximum load.

\section{Beam with Stirrups}

Consider now a beam with stirrups (Fig. 5). The stirrups cause the diagonal cracks due to shear to be more densely distributed. The first hairline cracks, shown by the thin dashed lines in Fig. 5(a), form near the neutral axis (with inclination about $45^{\circ}$ ) before the maximum load. These cracks later interconnect and form continuous major cracks at inclination angle $\theta$ with the horizontal (Fig. 5). These cracks run in the direction of the maximum principal compressive stress $\sigma_{\mathrm{II}}$, transmitting crack-bridging normal and shear stresses that are negligible compared to the compressive stresses in the struts between the cracks. This means that the resistance of concrete to diagonal tension may be neglected, $\sigma_{1} \approx 0$. This makes the truss statically determinate. It is this circumstance that makes the well-known simple analysis of the truss model possible.

The failure at maximum load is assumed to be caused by the progressive fracture of concrete in the compression struts between the major inclined cracks. Similar to beams without stirrups, a fracture band that consists of dense axial splitting microcracks first widens to its full width $h$ and then propagates sideways as shown in Fig. 5(b). For the case of a positive bending moment, this fracture band forms near the top of the beam and may be assumed to propagate horizontally, left or right, or both. The direction of the propagation of the fracture band is actually not important for the present analysis, and the same results would be obtained if the band propagated at other inclinations to the compression strut. An important point, however, is that the final length $h_{0}$ of the axial splitting cracks, that is, the final width $h_{0}$ of the band, is a material property, independent of the size of the beam. If the width $h_{0}$ of the band were proportional to beam depth $d$, there would be no size effect. Since it is less than proportional to $d$, there must be size effect.

Thus, the cause of the size effect is the localization of the compression failure of the strut into a fracture band of a fixed width and the growth of this band across the strut.

An important point is that the stirrups as well as the longitudinal steel bars are not necessarily yielding during the failure at maximum load. They might not have yielded before the fracturing of the strut began, or they may have yielded and unloaded. There is no reason why the yielding of steel should occur simultaneously with the progressive compression fracture.

The formation of the fracture band 12341 [Fig. 5(b)] may again be assumed to relieve the compression stress from the entire length of the compression struts in the region 12561 [Fig. 5(b)]. This causes a release of strain energy from the compression struts, which is then available to drive the propagation of the fracture band. This represents the mechanism of failure at maximum load.

With the stress relieved from the aforementioned compression struts, the beam acts essentially as shown in Fig. 5(c), as if there were a gap in concrete (provided the residual strength of crushed concrete is neglected). However, since the steel is not in general yielding, this does not represent a failure mechanism. A failure mechanism can be created only when a sufficient number of compression struts are crushed as shown in Fig. 5(d), in which case even nonyielding bars permit free movement because the bending resistance of the bars is negligible. However, this type of collapse mechanism corresponds to a state at which the load is already reduced to a very small value [such as state III in Fig. 5(e)]. Thus, the stress relief at maximum load does not imply the structure to become a mechanism.

First let us explain the size effect mechanism in the simplest possible terms. The area of the compression struts from which the compression is relieved, that is, area 12561 in Fig. 6, is proportional to $c d$, which is equal to $(c / d) d^{2}$. But since the failure is assumed to be geometrically similar for beams of different sizes (shown in Fig. 6), cld is a constant, and so the
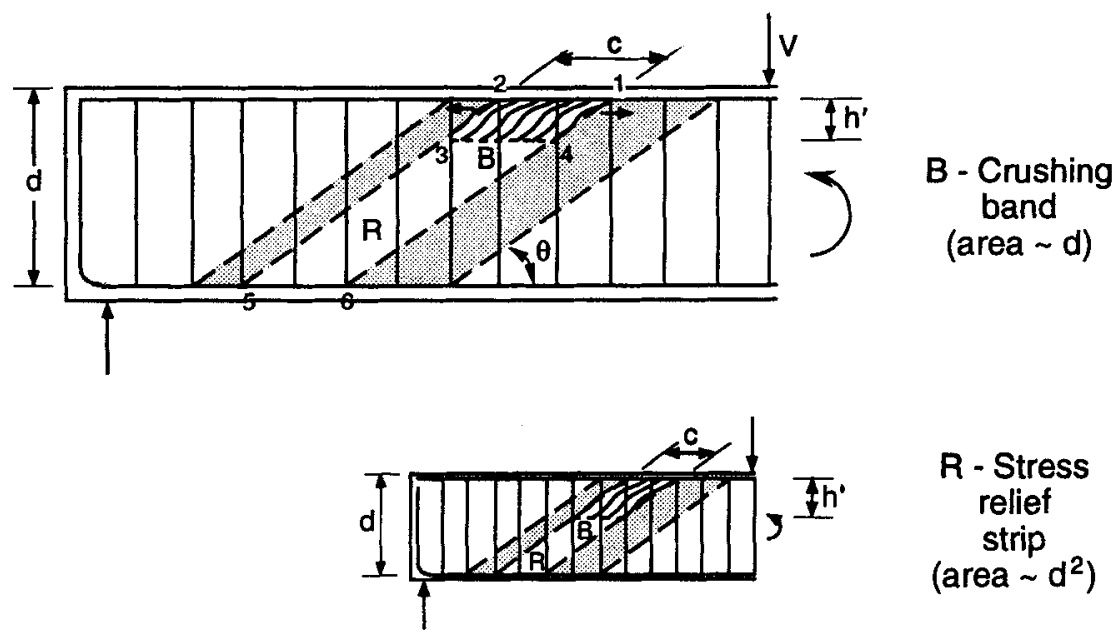

FIG. 6. Stress Redistribution into Cross-Hatched Portion of Compression Strut Caused by Propagation of Fracture Band, for Beams of Different Sizes (Simply Supported) 


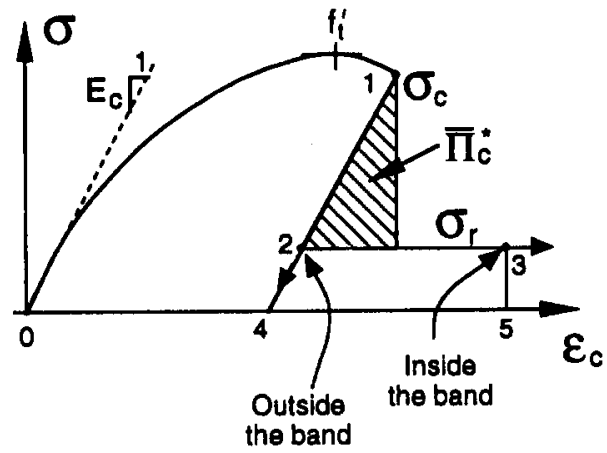

FIG. 7. Compression Stress-Strain Dlagram of Concrete with Unloading after Peak Stress and Area Representing the Strain Energy Release

area of the stress relief zone is proportional to $d^{2}$. The strain energy density before the stress relief is proportional to $v_{u}^{2} / 2 E_{c}$, and so the total energy release is proportional to $v_{u}^{2} d^{2}$. The area of the fracture band is proportional to $c h=$ (c/d)hd. Since both $h$ and $c / d$ are constant for beams of different sizes, the area of the fracture band is proportional to $d$, and so is the energy dissipated in the fracture band. So, considering the failures of geometrically similar beams of different sizes, $v_{u}^{2} d^{2}$ must be proportional to $d$, which means that $v_{u}$ must be proportional to $1 / \sqrt{d}$. Again, same as for the beam without stirrups, we thus obtain a size effect, and it is the strong size effect of LEFM. In practice, the size effect for smaller beam sizes is weaker because of the $R$-curve behavior of the fracture band 12341 .

We assume the stirrups to be uniformly distributed (smeared). Equilibrium of the forces in the compression struts, ties, and longitudinal bars [Figs. 6 and 5(f)] requires that

$$
\sigma_{c}=-\frac{F_{c}}{b d \cos \theta}=-\frac{v_{u} b d}{\sin \theta} \frac{1}{b d \cos \theta}=-\frac{2 v_{u}}{\sin 2 \theta}
$$

where $\theta=$ inclination of the compression struts; $F_{c}=$ compression force in the strut; and $\sigma_{c}=$ compression stress transmitted by the strut (which in general is not equal to the standard compression strength $f_{c}^{\prime}$ of concrete and depends on the size of the beam in a manner to be determined). Equilibrium on an inclined cross section of the beam parallel to the compression struts further requires that

$$
\sigma_{v}=\left(V s / A_{v} d\right) \tan \theta=v_{u} s b \tan \theta / A_{v}
$$

where $A_{v}=$ cross section of the stirrups; $s=$ spacing of the stirrups; and $\sigma_{\nu}=$ tensile stress in the stirrups, which in general is not equal to the yield stress. The stress in the longitudinal bars is obtained from the moment equilibrium condition in a cross section and is $\sigma_{s}=M / A_{s} k_{b} d$, in which $M=$ bending moment, $A_{s}=$ cross section area of the longitudinal bars, and $k_{b} d=$ arm of the internal force couple in the cross section. It is assumed that the steel bars are designed strong enough to resist stresses $\sigma_{c}$ and $\sigma_{v}$ safely.

We do not attempt to determine the angle $\theta$ of the diagonal cracks and the struts by fracture analysis, since the diagonal cracks delineating the struts are assumed to be formed before the maximum load, and not during failure. Rather we adopt the method introduced into the truss model by Collins (1978) in his compression field theory, in which he used the compatibility condition for the average strains in the truss in a similar way as Wagner (1929) used the compatibility condition for approximate analysis of the shear buckling of the webs of steel beams (Collins and Mitchell 1981). The average strains of the truss are defined as the strains of a homogeneously deforming continuum that is attached to the joints of the truss at the nodes (tops and bottoms of the stirrups). According to the Mohr cir- cle shown in Fig. 5(f) (in which $\varepsilon$ denotes the strains, and $\varepsilon_{t}$ is the strain in the longitudinal bars), the overall compatibility of the average strains of the struts, the stirrups, and the longitudinal bars requires that

$$
\tan ^{2} \theta=\frac{\varepsilon_{v}-\varepsilon_{c}}{\varepsilon_{l}-\varepsilon_{c}}=\frac{\left(\sigma_{v} / E_{s}\right)-f\left(\sigma_{c}\right)}{\left(\sigma_{s} / E_{s}\right)-f\left(\sigma_{c}\right)}
$$

Here the strains have been expressed in terms of the stresses assuming the steel not to be yielding and denoting by $f\left(\sigma_{c}\right)$ the stress-strain diagram of concrete. [For the precise method in which the strains entering (18) are calculated, see Collins (1978) and Collins and Mitchell (1981)]. The foregoing calculation, of course, requires that the diagonal cracks and the struts be aligned with the direction of the compressive principal strain, which coincides with the direction of the compressive principal stress.

The fracture analysis begins by expressing the potential energy change (Fig. 7) caused by the formation of the fracture band of length $c$ at constant load-point displacement

$$
\Pi_{c}=-\frac{\left(\sigma_{c}-\sigma_{r}\right)^{2}}{2 E_{c}} b c d
$$

The minus sign reflects the fact that this is an energy loss rather than gain.

The stress $\sigma_{r}$ in the foregoing equation represents the residual compression strength of the fracture band in concrete. In this study the residual compression fracture strength $\sigma_{r}$ is considered an empirical property. However, it can be mathematically expressed on the basis of the concept of internal buckling of a material heavily damaged by axial splitting microcracks, as proposed in Bažant and Xiang (1996).

The energy release rate may be calculated as

$$
\mathscr{G}=-\left[\frac{\partial \Pi_{c}}{\partial c}\right]_{u}=\frac{\left(\sigma_{c}-\sigma_{r}\right)^{2}}{2 E_{c}} b d
$$

The energy dissipation rate (fracture resistance) of the fracture band is again given by (5), i.e., $\mathscr{R}=G_{f} b h / s_{c}$, in which the width of the fracture band may be assumed to evolve again according to (6), i.e., $h=h_{0} c /\left(w_{0}+c\right)$.

Substituting now (16) and (17) into (20), and using the fracture propagation criterion, i.e., $\mathscr{G}=\mathscr{R}$ as in (8), we obtain an equation that can be easily solved for $v_{u}$. This provides the result

$$
v_{u}=v_{p}\left(1+\frac{d}{d_{0}}\right)^{-1 / 2}+v_{r}
$$

in which we introduced the notations

$$
\begin{gathered}
d_{0}=w_{0} \frac{d}{c} \\
v_{r}=\frac{\sin 2 \theta}{2} \sigma_{r} ; \quad v_{p}=K_{c} \sqrt{\frac{h_{0}}{2 s_{c} w_{0}}} \sqrt{\frac{c}{d}} \sin 2 \theta
\end{gathered}
$$

The size effect described by (21) is plotted in Fig. 4 in two ways, in terms of $\log v_{u}$ and $\log \log \left(v_{u}-v_{r}\right)$. By virtue of the residual compression strength, the nominal shear strength of the beam tends at infinite size to a finite value. An equation of the form of (21) was proposed on the basis of general considerations in Bažant (1987).

The question whether the confinement of concrete by stirrups suffices to cause the residual compression strength $\sigma_{r}$, and thus the residual nominal strength $v_{r}$, to be nonzero needs to be studied further. 


\section{ANALYSIS BASED ON STRESS REDISTRIBUTION AND COMPLEMENTARY ENERGY}

The truss model also allows an easy alternative calculation of the energy release on the basis of complementary energy $\Pi_{c}^{*}$. For the sake of simplicity, we now consider the residual strength $v_{r}=0$, although a generalization to finite $v_{r}$ would be feasible.

In the truss model, we isolate the representative cell limited by the shaded zone in Fig. 6 . This cell must alone be capable to resist the applied shear force $V$. The fracturing of concrete in the band 12341 (Fig. 6) is considered to relieve the stress completely from the inclined strip 12561. If the applied shear force $V$ is kept constant, the stress in the cell must redistribute such that all of the compression force in the inclined strut is carried by the remaining strips, shaded in Fig. 6. After that, all of the complementary energy in concrete in the cell is contained in the shaded strips and (upon noting the energy density given by the shaded area in Fig. 7) may be expressed as $\Pi_{c}^{*}=\left(\bar{\sigma}_{c}^{2} / 2 E_{c}\right) \mathscr{V}$ in which $\mathscr{V}=b(d \cos \theta-c \sin \theta) d / \sin \theta=$ volume of the shaded strips (Fig. 6), $\bar{\sigma}_{c}=F_{c} / b(d \cos \theta-$ $c \sin \theta)=$ average normal stress in the direction of the strut, and $F_{c}=V / \sin \theta=v_{u} b d / \sin \theta=$ compression force transmitted by the strut. This yields, for the complementary energy after the stress redistribution at constant shear force $V$, the expression

$$
\Pi_{c}^{*}=\left(\frac{v_{u} d}{\sin \theta}\right)^{2} \frac{b d}{2 E_{c}(d \cos \theta-c \sin \theta) \sin \theta}
$$

As is well known from fracture mechanics [e.g., Bažant and Cedolin (1991), section 12.1[, the energy release rate is obtained by differentiation of the complementary energy at constant load (or constant shear force $V$ )

$$
\mathscr{G}=\left[\frac{\partial \Pi_{c}^{*}}{\partial c}\right]_{v}=\frac{v_{u}^{2} b d^{3}}{2 E_{c} \sin ^{2} \theta(d \cos \theta-c \sin \theta)^{2}}
$$

This must be equal to the energy dissipation rate, which is given by the following equations, same as before:

$$
\mathscr{R}=\frac{b h}{s_{c}} G_{f} ; \quad h=\frac{h_{0} c}{w_{0}+c}
$$

There is now one difference from the previous approach. In (20), the energy release rate was constant, while in (25) it increases with $c$. This difference should not surprise since both solutions are approximate. In the case of variable $\mathscr{G}$, which is a typical case in fracture mechanics, the crack length at maximum load, that is, at a loss of stability, need not be considered as empirical, as done in our previous calculation based on the potential energy change, but can be calculated from the stability criterion. It is well known that, at the limit of stability, the curve of energy release rate at constant load must be tangent to the $R$-curve (Bažant and Cedolin 1991, chapter 12)

$$
\frac{\partial \mathscr{G}}{\partial c}=\frac{d \mathscr{R}}{d c}
$$

[This stability criterion could not be applied to the previous case with (20), because in that case, due to the approximations made, we had $\partial \mathscr{G} / \partial c=0$ and thus $c$ was interdeterminate.] Because $\mathscr{G}=\mathscr{R}$, an equivalent condition is

$$
\frac{1}{\mathscr{G}} \frac{\partial \mathscr{G}}{\partial c}=\frac{1}{\mathscr{R}} \frac{d \mathscr{R}}{d c}
$$

which is more convenient. We may now substitute here the expressions in (25) and (26), and carry out the differentiations. This leads to a quadratic equation for $c / d$, whose only real solution is

$$
\frac{c}{d}=\frac{3 w_{0}}{4 d}\left(-1+\sqrt{1+\frac{8 d}{9 w_{0}} \cot \theta}\right)
$$

This represents a theoretical expression for the length of the crushing band at maximum load (i.e., at stability loss).

It may now be observed that $c / d$ tends to zero as the size $d$ $\rightarrow \infty$. In that limiting case the stress relief region would become an infinitely narrow strip, which would not be a realistic model. Therefore, (29) is meaningful only for sufficiently small sizes. For this reason, and for the sake of simplicity, we consider the second term under the square root in (29) to be small compared to 1 . Because $\sqrt{1+2 x} \approx 1+x$ when $x<<$ 1 , (29) for small $d$ yields the approximation:

$$
\frac{c}{d}=\frac{\cot \theta}{3}
$$

Substituting this into the fracture propagation criterion $\mathscr{G}=\mathscr{R}$, along with (25) and (26), we obtain an equation whose solution furnishes the simple result

$$
v_{u}=v_{p}\left(1+\frac{d}{d_{0}}\right)^{-1 / 2}
$$

in which we have introduced the notations

$$
d_{0}=3 w_{0} \tan \theta ; \quad v_{p}=K_{c} \sqrt{\frac{2 h_{0}}{27 s_{c} w_{0}}} \sin 2 \theta \sqrt{\cot \theta}
$$

The result we have obtained has the same form as (21), although the expressions for the size effect constants $d_{0}$ and $v_{p}$ are partly different. The differences reveal the degrees of uncertainty caused by the simplifications of analysis we made. The comparison of (21) and (31) indicates that the general form of the size effect we obtained ought to be realistic, although the coefficients $d_{0}$ and $v_{p}$ cannot be fully predicted by the theory, but must be calibrated on the basis of experiments.

\section{SIZE EFFECT ON NOMINAL STRESS AT CRACKING LOAD}

It has been suggested that the size effect might not be of concern because the current ACI code [ACI 318; Building (1992)] and other codes are intended to provide safety against the cracking load at which large diagonal cracks form, rather than against the collapse load, which is considerably higher. However, the nominal stress corresponding to the cracking load also exhibits size effect. There are two possibilities to define the cracking load.

\section{Load-Causing Cracks of Given Relative Depth}

One possibility is to define the cracking load as the load that produces initial diagonal shear cracks of a depth $d_{i}$ representing a given percentage of beam depth $d$, i.e., such that the ratio $d_{i} / d$ is a given constant [Fig. 8(a)], say 0.5. We imagine an array of the initial cracks, as shown in Fig. 8(a). The formation of each initial crack causes stress redistribution in triangular zones 1321 and 1341, shaded in Fig. 8(a). (In contrast to Fig. 6, the stress relief zones are not strips, nor elongated triangles, because the material is not orthotropically damaged before the initial cracks form.) For the sake of simplicity, these zones may be assumed to consist of triangles with angles roughly $\theta=45^{\circ}$, each two triangles making a square. The shape of these zones and the length of the initial cracks obviously determines their spacing.

Before the initial diagonal cracks form, the vertical stress in the beam is 0 , and so the stirrups have no stress, while shear force $V$ is resisted by shear stresses in concrete taken approxi- 
(a)
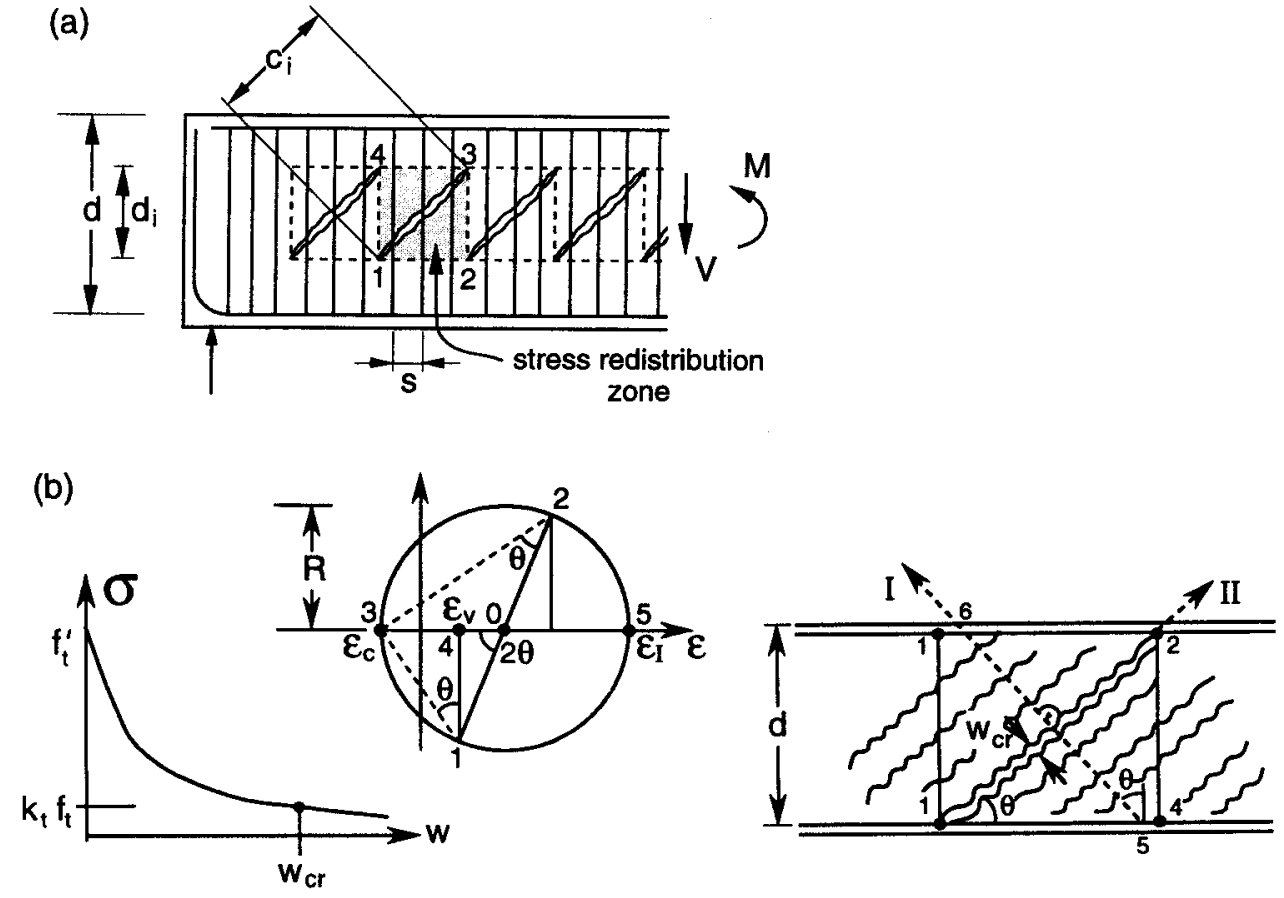

(c)
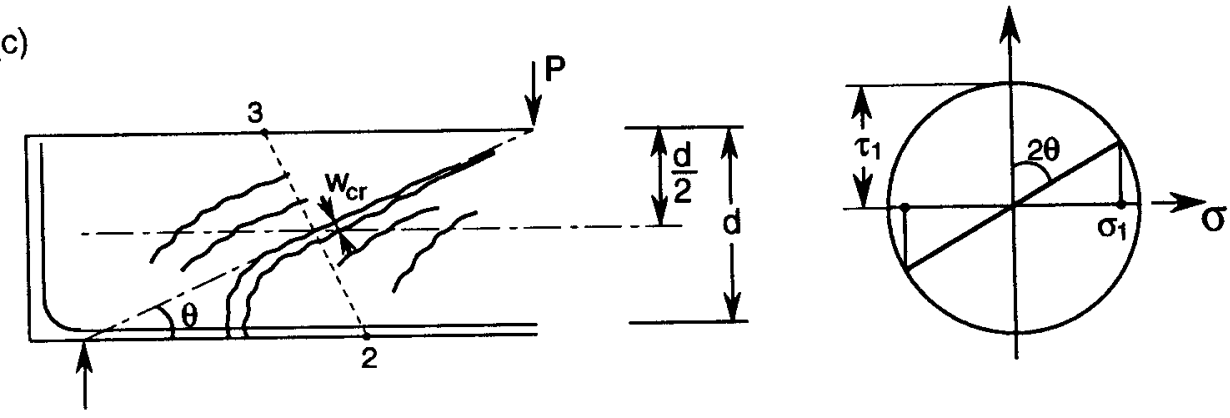

FIG. 8. (a) Stress Redistribution Zones for Initial Diagonal Shear Cracks; (b) Tensile Stress-Displacement Diagram for Opening of Cohesive Crack, Localization of Openings of Diagonal Cracks into One Major Diagonal Crack in Beam with Stirrups, and Mohr Circle of Strains; (c) Localization of Openings of Diagonal Cracks into One Major Crack In Beam without Stirrups and Mohr Circle of Stresses

mately as $v=V / b d$. The strain energy initially contained in the shaded square cell in Fig. $8(\mathrm{a})$ is $\Pi_{0}^{*}=\left(v^{2} / 2 G_{c}\right) b\left(c_{i} \cos \theta\right)$. $\left(c_{i} \sin \theta\right)=v^{2}(1+\nu) b c_{i}^{2} \sin \theta \cos \theta / E_{c}$ where $G_{c}=E_{c} / 2(1$ $+\nu)=$ elastic shear modulus of concrete, $\nu=$ Poisson ratio $(\nu \approx 0.18)$, and $c_{i}$ is defined in Fig. 8(a). After the initial cracks form, the diagonal tensile stress in the shaded square zone is reduced to 0 and the applied shear stress $v$ is then carried by truss action in the cell, i.e., by tensile stress $\sigma_{v}$ in the vertical stirrups, given by (17), and by diagonal compressive stress $\sigma_{c}$, given by (16). So the strain energy contained in the cell after the initial cracks form is approximately calculated as $\Pi_{1}^{*}=$ $\left.\sigma_{c}^{2} / 2 E_{c}\right) b\left(c_{i} \sin \theta\right)\left(c_{i} \cos \theta\right)+\left(\sigma_{v}^{2} / 2 E_{s}\right) A_{v}\left(c_{i}^{2} / s\right) \sin \theta \cos \theta$ where $\sigma_{v}=v b s \tan \theta / A_{v} \sigma_{c}=-v / \sin \theta \cos \theta$. For the sake of simplicity, we assume $\theta=45^{\circ}$. The complementary energy change per crack at constant $V$ is $\Delta \Pi^{*}=\Pi_{1}^{*}-\Pi_{0}^{*}$, which yields

$$
\Delta \Pi^{*}=\frac{b c_{i}^{2} v^{2}}{E_{c}}\left(\frac{1-v}{2}+\frac{b s}{4 n A_{v}}\right) ; \quad n=\frac{E_{s}}{E_{c}}
$$

Consider now the final infinitesimal crack length increment $d c_{i}$, by which the crack size $c_{i}$ is reached [the shaded square zone in Fig. 8(a) grows with $c_{i}$, and at the end of this increment it touches the square zone corresponding to the adjacent crack]. During this increment, the change of complementary energy is $\left[\partial\left(\Delta \Pi^{*}\right) / \partial c_{i}\right] d c_{i}$. This must be equal to the energy consumed and dissipated by the crack, which is $b R d c_{i} ; R$ is the crack resistance, which represents the critical energy release rate required for crack growth. In general $R$ depends on $c_{i}$, representing the so-called $R$-curve behavior. This dependence may be approximately described as

$$
R=G_{f} \frac{c_{i}}{c_{0}+c_{i}}
$$

where $c_{0}=$ a positive constant. For large enough $c_{i}, R=G_{f}=$ fracture energy of the material. The balance of energy during the crack length increment requires that

$$
\frac{\partial\left(\Delta \Pi^{*}\right)}{\partial c_{i}} d c_{i}=b R d c_{i}
$$

Substituting here (34), we obtain an equation whose solution yields for the size effect on the applied nominal shear stress $v_{c r}$ at initial cracking the following equation:

$$
v_{c r}=v_{c r 0}\left(1+\frac{d}{d_{c r 0}}\right)^{-1 / 2}
$$

in which the following constants have been introduced:

$$
d_{c r 0}=c_{0} \frac{d}{c_{i}} ; \quad v_{c r 0}=\left[\frac{E_{c} G_{f}}{c_{0}}\left(2+\frac{b s}{2 n A_{v}}-\frac{1+v}{2}\right)^{-1}\right]^{1 / 2}
$$

Note that the ratio $d / c_{i}$ is assumed to be a given constant by which the cracking load is defined. Eq. (37) shows that the 
applied nominal shear stress at cracking follows the size effect law proposed by Bažant (1984). As a special case, this equation applies to a beam without stirrups $\left(A_{v}=0\right)$.

\section{Load-Causing Cracks of Given Opening Width}

Another possibility is to define the cracking load as the load that produces cracks of a given critical width $w_{c r}$. Consider first the beams with stirrups. Under a certain load, a number of parallel diagonal cracks may initiate. The cracks are cohesive. This means that crack-bridging stresses are transmitted across the cracks (due to aggregate pullout and other phenomena). Reduction of the crack-bridging stress to zero requires a considerable opening displacement of the crack, as is clear from the typical stress-displacement diagram used in the cohesive (fictitious) crack model; see Fig. 8(b). Furthermore, it is known that when many parallel cracks form, only one of them may open widely while the others unload and close. In fact, such a localization of crack openings into one among many parallel cracks is a necessity unless there is enough reinforcement to ensure a stiffening rather than softening behavior [see chapter 12 in Bažant and Cedolin (1991)]. Thus, unless the stirrups are extremely strong, the situation as shown in Fig. 8(b) must be expected.

Since the reduction of the crack-bridging stress to zero requires a very large opening, we consider that the stress is reduced only to a certain small but finite fraction $k_{t}$ of the tensile strength $f_{i}^{\prime}$ of concrete. Consider now the relative displacement between points 5 and 6 at the bottom and top of the beam, lying on a line normal to the cracks after one large crack forms. This displacement may be approximately expressed as $\Delta u_{t}=(d / \cos \theta)\left(k_{t} f_{i}^{\prime} / E_{c}\right)+w_{c r}$, in which $d / \cos \theta$ is the length of the line segment 56 , and $w_{c r}$ is a critical crack opening displacement at which the crack bridging stress is reduced from $f_{i}^{\prime}$ to $k_{t} f_{t}^{\prime}$ [Fig. 8(b)]. Dividing this by the length of segment 56, we obtain the average normal strain in the direction orthogonal to the diagonal cracks:

$$
\bar{\varepsilon}_{l_{c r}}=\frac{\Delta u_{l}}{d / \cos \theta}=\frac{k_{t} f_{i}^{\prime}}{E_{c}}+\frac{w_{c r} \cos \theta}{d}
$$

Displacement $\Delta u_{1}$ or strain $\bar{\varepsilon}_{l_{c r}}$ must be compatible with the overall deformation of the truss. Imagining the nodes of the truss to be attached to a homogeneously deforming continuum, this condition means that strain $\bar{\varepsilon}_{l_{c r}}$ must be tensorially compatible with the normal strains $\varepsilon_{c}$ in the inclined struts and $\varepsilon_{b}$ in the vertical stirrups, as well as with the principal direction angle $\theta$. This strain compatibility condition may be easily deduced from the Mohr circle in Fig. $8(\mathrm{~b})$. Noting that $14=$ $\left(\varepsilon_{v}-\varepsilon_{c}\right) \cot \theta, R=\overline{05}=\overline{01}=\overline{14} / \sin 2 \theta=\left(\varepsilon_{v}-\varepsilon_{c}\right) \cot \theta / \sin$ $2 \theta, \bar{\varepsilon}_{I}=\varepsilon_{c}+2 R$, we obtain the following expression for the average strain in the direction orthogonal to the diagonal cracks:

$$
\bar{\varepsilon}_{I}=\varepsilon_{c}+\frac{\varepsilon_{v}-\varepsilon_{c}}{\sin ^{2} \theta}=\frac{\varepsilon_{v}}{\sin ^{2} \theta}-\varepsilon_{c} \cot ^{2} \theta
$$

In terms of the stresses, $\varepsilon_{v}=\sigma_{v} / E_{s}, \varepsilon_{c}=\sigma_{c} / E_{c}$, in which $E_{s}=$ elastic modulus of steel and $E_{c}=$ secant modulus for the compression strut at the moment the diagonal cracks form, which is less than the initial elastic modulus but larger than the secant modulus for the peak stress point of the compression stressstrain diagram. Here, the stresses may be expressed from the equilibrium conditions of the truss: $\sigma_{v}=v_{c r} s b \tan \theta / A_{v}, \sigma_{c}=$ $-2 v_{c r} / \sin 2 \theta$ where $A_{v}=$ cross section area of one stirrup, and $v_{c r}=V_{c r} / b d=$ nominal stress corresponding to the shear force at the moment of formation of large diagonal cracks. Substituting these expressions into (40), we obtain

$$
\bar{\varepsilon}_{t}=\frac{2}{\sin 2 \theta}\left(\frac{s b}{A_{v} E_{s}}+\frac{\cot ^{2} \theta}{E_{c}^{\mathrm{sec}}}\right) v_{c r}
$$

Setting this expression equal to (39), we obtain an equation for $v_{c r}$, the solution of which furnishes the result

$$
v_{c r}=v_{\infty}+v_{0} \frac{w_{c r}}{d}
$$

Here we introduced the notations

$$
v_{0}=\sin \theta \cos ^{2} \theta\left(\frac{s b}{A_{v} E_{s}}+\frac{\cot ^{2} \theta}{E_{c}^{\mathrm{sec}}}\right)^{-1} ; \quad v_{\infty}=\frac{k_{t} f_{i}^{\prime} v_{c r}^{0}}{E_{c} \cos \theta}
$$

Eq. (42) describes a size effect that is an alternative to (37). The asymptotic constant value $v_{\infty}$ exists because we assume that the critical crack opening $w_{c r}$ corresponds to nonzero crack bridging stress $k_{t} f_{i}^{\prime}$; if this stress were neglected, we would obtain $v_{\infty}=0$.

Consider now a beam without stirrups. This problem is more complicated because there is no truss model that could give the value of the average strain along line 2-3 in Fig. 8(c). Other simplifications are therefore needed to obtain a simple result. We will assume that the normal strains along the line segment $2-3$ in Fig. 8(c) may be approximated according to the beam theory. The shear stress in the vertical plane is distributed parabolically, and so at point 1 at middepth of the beam (neutral axis) it has the value $\tau_{1}=1.5 v_{c r}$. From the Mohr circle in Fig. 8(c), we then obtain the normal stress $\sigma_{1}$ in the direction 2-3 at point 1 and the corresponding strain: $\varepsilon_{1}=$ $1.5 v_{c r} \sin 2 \theta / E_{c}$. The normal strain in the direction 2-3 may also be assumed distributed parabolically, in which case the average normal strain along this line is $\bar{\varepsilon}_{1}=v_{c r} \sin 2 \theta / E_{c}$. Multiplying this by the length of segment $2-3$, we obtain the relative displacement between points 2 and 3 in the direction 2-3:

$$
\Delta u_{2-3}=\bar{\varepsilon}_{1} \frac{d}{\cos \theta}=\frac{v_{c r}}{E_{c}} \sin 2 \theta \frac{d}{\cos \theta}
$$

At the same time, in analogy to (39),

$$
\Delta u_{2-3}=\frac{d}{\cos \theta} \frac{k_{t} f_{t}^{\prime}}{E_{c}}+w_{c r}
$$

Equating the last two expressions, we obtain the same equation as (43), that is, $v_{c r}=v_{\infty}+v_{0}\left(w_{c} / d\right)$, in which we now make the notations

$$
v_{\infty}=\frac{2 k_{i} f_{i}^{\prime}}{3 \sin 2 \theta} ; \quad v_{0}=\frac{E_{c} w_{c r}}{3 \sin \theta}
$$

\section{CONCLUSIONS}

The classical, widely used, truss model (or strut-and-tie model) for the shear failure of reinforced concrete beams can be modified to capture the fracture behavior characterized by an energy release and localization of damage into a fracture band within a portion of the compressed concrete strut.

If the analysis of the maximum load based on the truss model is valid, the concrete strut must, during the portion of loading history in which the maximum load is reached, undergo compression softening in a propagating fracture band (consisting of splitting cracks or shear crack inclined to the strut).

Analysis of the energy release into the fracture band shows that a size effect on the nominal strength at shear failure of a reinforced concrete beam must occur and that it should approximately follow the size effect law proposed by Bažant (1983, 1984, 1987). Conversely, the fracture behavior of the truss model (strut-and-tie model), particularly the damage localization with energy release, provides an explanation of the size effect widely observed in many tests, beginning with those of Kani (1967). 
The applied nominal shear stress that causes the initial large diagonal cracks also exhibits a size effect. The law of this size effect depends on how large diagonal cracks are defined.

The size effect formulas derived here have not yet been calibrated and verified by the available test results for beams. The expressions for the coefficients in these formulas need to be studied further in order to develop a design procedure incorporating the size effect.

\section{ACKNOWLEDGMENTS}

Partial financial support for the study of size effect in shear failure of concrete was provided by the Center for Advanced Cement Based Materials at Northwestern University and by NSF grant 9531299. Thanks are due to Professor H. Okamura for stimulating discussions during the stay of the writer at the University of Tokyo under Japan Society for Promotion of Science Fellowship.

\section{APPENDIX I. SIZE EFFECT IN ORTHOTROPICALLY DAMAGED MATERIAL}

A clue to the shape of the stress relief zones considered in the preceding analysis may be obtained by comparing the stress relief zones in isotropic and highly orthotropic materials. For isotropic materials, the stress relief zone that gives a good approximation to the nominal strength $\sigma_{N}$ is shown in Fig. 9(a). For the case of highly orthotropic materials such as a composite with unidirectional fiber reinforcement, the stress relief zone becomes highly elongated and reaches to the end of a specimen. A similar situation arises in compression failure, in which long and densely distributed axial splitting cracks form before failure [Fig. 9(c)]. Propagation of a fracture band transversely to the direction of compression releases stress from a zone that is so elongated that it may be approximately considered as a strip with parallel boundaries.

In Fig. 9(a), the energy consumed by fracture is proportional to the crack length $c$, but because $c / d$ is assumed constant when the specimen size $d$ is varied, the energy release is also proportional to $d$. On the other hand, the energy release is proportional to the area of the stress relief zones, which is proportional to $c d=(c / d) d^{2}$ or to $d^{2}$, which means the energy release is proportional to $\sigma_{N}^{2} d^{2}$. Thus, $\sigma_{N}^{2} d^{2}$ must be proportional to $d$, which means that the nominal strength $\sigma_{N}$ must be proportional to $1 / \sqrt{d}$. The same is true for the situation in Fig. 9(c).

For the case of compression failure, the area of the fracture

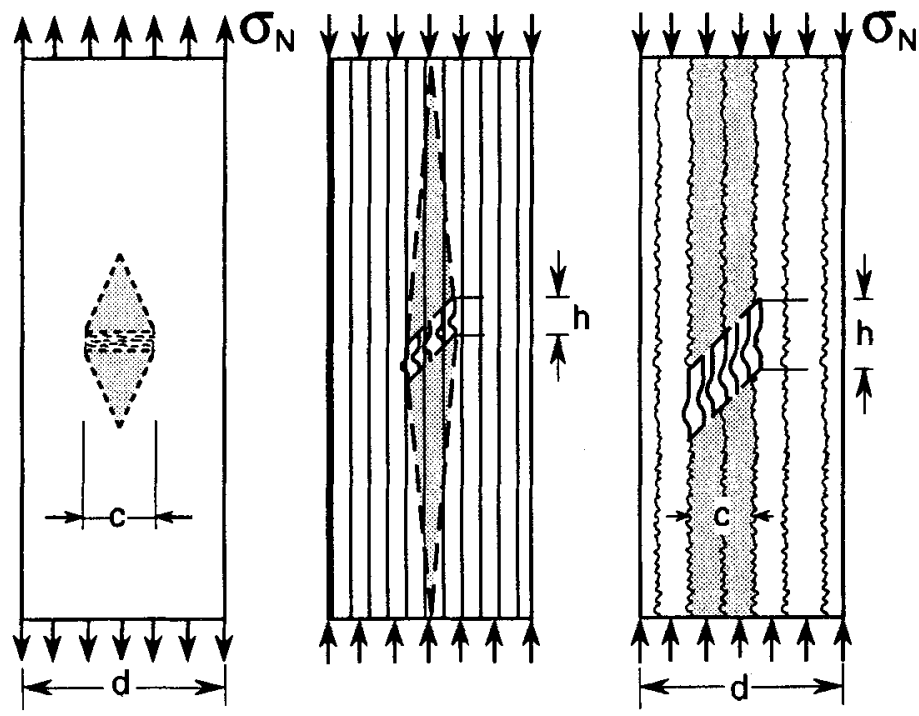

FIG. 9. Stress Relief Zones in (a) Isotropic Panel with Tensile Crack; (b) Highly Orthotropic Panel with Tensile Crack or Crack Band; and (c) Compressed Panel with Dense Axial Splitting Cracks and Compression Fracture Band band is proportional to $c$, and thus to $d$ which characterizes energy dissipation. The area of the strip from which the stress is relieved is proportional to $c d=(c / d) d^{2}$, that is, to $d^{2}$, which means that the energy release is proportional to $\sigma_{N}^{2} d^{2}$. Since this must be proportional to $d$ according to energy balance, the size effect is again such that $\sigma_{N}$ is proportional to $1 / \sqrt{d}$.

In the full equation form, the energy relese is

$$
\Pi_{c}^{*}=\frac{\sigma_{N}^{2}}{2 E_{c}} b c d
$$

while the energy consumed is

$$
W_{f}=b G_{f} h \frac{c}{s_{c}}
$$

From the condition $\partial \Pi_{c}^{*} / \partial c=\partial W_{f} / \partial c$ one obtains the equation $\left(\sigma_{N}^{2} / 2 E_{c}\right) b d=G_{f} b h / s_{c}$. Solving for the nominal strength, one obtains the size effect expression for the compression failure

$$
\sigma_{N}=\sqrt{\frac{2 h}{s_{c}} E_{c} G_{f}} \frac{1}{\sqrt{d}}
$$

This is of course a simplified formulation giving a size effect of LEFM type, In practice, due to $R$-curve behavior or other phenomena, an equation of the type of (21) may be derived in general for a panel failing in compression.

\section{APPENDIX II. REFERENCES}

Bahl, N. S. (1968). “Über den Einfluss der Balkenhöhe auf Schubtragfähigeit von einfeldrigen Stahlbetonbalken mit und ohne Schubbewehrung," Dissertation, Universităt Stuttgart, Germany (in German).

Bažant, Z. P. (1983). "Fracture in concrete and reinforced concrete." Preprints, IUTAM Prager Symp. on Mech. of Geomat.: Rocks, Concretes, Soil, Z. P. Bažant, ed., Northwestern University, Evanston, Ill., $281-316$.

Bažant, Z. P. (1984). "Size effect in blunt fracture: Concrete, rock, metal." J. Engrg. Mech., ASCE, 110(4), 518-535.

Bažant, Z. P. (1987). "Fracture energy of heterogeneous material and similitude." Preprints, SEM-RILEM Int. Conf. on Fracture of Concrete and Rock, S. P. Shah and S. E. Swartz, eds., Soc. for Exper. Mech., $390-402$

Bažant, Z. P. (1993). "Scaling laws in mechanics of failure." J. Engrg. Mech., ASCE, 119(9), 1828-1844.

Bažant, Z. P. (1995a). "Scaling theories for quasibrittle fracture: Recent advances and new directions." Fracture Mechanics of Concrete Structures, F. H. Wittmann, ed., Aedificatio Publishers, Freiburg, Germany, $515-534$.

Bažant, Z. P. (1995b). "Scaling of quasibrittle fracture and the fractal question."' J. Mat. and Technol., 177(Oct.), 361-367.

Bažant, Z. P. (1997a). "Scaling of quasibrittle fracture: Asymptotic analysis." Int. J. Fracture, 83(1), 19-40.

Bažant, Z. P. (1997b). "Scaling of quasibrittle fracture: Hypotheses of invasive and lacunar fractality, their critique and Weibull connection." Int. J. Fracture, 83(1), 41-65.

Bažant, Z. P., and Cao, Z. (1987). "Size effect in punching shear failure of slabs." ACI Struct. J., 84(1), 44-53.

Bažant, Z. P., and Cedolin, L. (1991). Stability of structures: elastic, inelastic, fracture and damage theories. Oxford University Press, New York.

Bažant, Z. P., and Chen, E.-P (1997). "Scaling of structural failure." Appl. Mech. Rev., 50(10), 593-627.

Bažant, Z. P., and Kazemi, M. T. (1991). "Size effect on diagonal shear failure of beams without stirrups." ACI Struct. J., 88(3), 268-276.

Bažant, Z. P., and Kim, J.-K., (1984). "Size effect in shear failure of longitudinally reinforced beams." $A C I J ., 81,456-468$; Disc. \& Closure 82 (1985), 579-583.

Bažant, Z. P., and Kim. J.-K. (1985). "Discussion and Closure of 'Size effect in shear failure of longitudinally reinforced beams." " $A C I J$., $82,579-583$

Bažant, Z. P., Ožbolt, J., and Eligehausen, R. (1994). "Fracture size effect: Review of evidence for concrete structures." J. Struct. Engrg., ASCE, $120(8), 2377-2398$.

Bažant, Z. P., and Planas, J. (1997). Fracture and size effect in concrete and other quasibrittle materials. CRC Press, Boca Raton, Fla.

Bažant, Z. P., and Sun, H.-H. (1987). "Size effect in diagonal shear fail- 
ure: Influence of aggregate size and stirrups." ACI Mat. J., 84(4), $259-272$.

Bažant, Z. P., and Xi, Y. (1991). "Statistical size effect in quasi-brittle structures: II. Non local theory." J. Engrg. Mech., 117(11), 2623 2640.

Bažant, Z. P., Xi, Y., and Reid, S. G. (1991). "Statistical size effect in quasi-brittle structures: I. Is Weibull theory applicable?"' J. Engrg. Mech., ASCE, 117(11), 2609-2622.

Bažant, Z. P., and Xiang, Y. (1996). "Size effect in compression fracture: splitting crack band propagation." J. Engrg. Mech., ASCE, 123(2), $162-172$.

Biot, M.A. (1965). Mechanics of incremental deformations. John Wiley \& Sons, New York.

Building Code Requirements for Reinforced Concrete. (1992). ACI 318 89 (Revised 1992), Am. Concrete Inst., Detroit, Mich.

Carpinteri, A., Chiaia, B., and Ferro, G. (1994). "Multifractal scaling for the nominal strength variation of concrete structures." Size effect in concrete structures, H. Mihashi, H. Okamura, and Z. P. Bažant, eds. E \& FN Spon, London, U.K., 193-206.

Carpinteri, A., Chiaia, B., and Ferro, G. (1995). "Size effects on nominal tensile strength of concrete structures: Multifractality of material ligaments and dimensional transition from order to disorder." Mat. and Struct., 28(7), 311-317.

Carpinteri, A., Ferro, G., and Intervenizzi, S. (1995). Fracture mechanics of concrete structures, F. H. Wittmann, ed., Aedificatio Publishers, Freiburg, Germany, 557-570.

Chana, P. S. (1981). "Some aspects of modelling the behaviour of reinforced concrete under shear loading." Tech. Rep. No. 543, Cement and Concrete Association, Wexham Springs, U.K.

Collins, M. P. (1978). "Towards a rational theory for RC members in shear." J. Struct. Div., ASCE, 104(4), 396-408.

Collins, M. P., and Mitchell, D. (1980). "Shear and torsion design of prestressed and non-prestressed concrete beams." J. Prestressed Concrete Inst., 25(5), 32-100.

Collins, M. P., and Mitchell, D. (1981). "Discussion of 'Shear and torsion design at prestressed and non-prestressed concrete beams.", J. Prestressed Concrete Inst., 26(6), 96-118.

Collins, M. P., and Mitchell, D. (1991). Prestressed concrete structures. Prentice Hall, Englewood Cliffs, N.J.

Collins, M. P., Mitchell, D., Adebar, P., and Vecchio, F. J. (1996). "General shear design method.' ACI Struct J., 93(1), 36-45.

Design of concrete structures, part I: General rules and rules for buildings. (1991). Eurocode No. 2.

Design Specification of Concrete Structures. (1986). Japan Soc. of Civ. Engrs., Concrete Cormmittee, Giho-do Co. Ltd., Tokyo, Japan.

Hsu, T. T. C. (1988). "Softened truss model theory for shear and torsion." ACI Struct. J., 85(6), 624-635.

Hsu, T. T. C. (1993). Unified theory of reinforced concrete. CRC Press, Boca Raton, Fla.

Hsu, T. T. C., and Zhang, L.-X. (1996). "Tension stiffening in reinforced concrete membrane elements." ACI Struct. J., 93(1), 108-115.

Iguro, M., Shioya, T., Nojiri, Y., and Akiayama, H. (1985). “Experimental studies on shear strength of large reinforced concrete beams under uniformly distributed load." Concrete Library Int., Japan Soc. of Civ. Engrs., No. 5, 137-154 (English translation of 1984 article in Proc., JSCE).

Kani, G. N. J. (1967). "Basic facts concerning shear failure." $A C I J$, 64(3), 128-141.

Khorasgany, M. G. (1994). "Size effect in the shear failure of normal and high strength reinforced concrete beams." $\mathrm{PhD}$ thesis, Univ. of Missouri, Columbia.

Kupfer, H. (1964). "Erweiterung der Mörch-schen Fachwerkanalogie mit Hilfe des Prinzips vom Minimum der Formänderungsarbeit." ("Generalization of Mörsch's truss analogy using the principle of minimum strain energy." ') Bull. d'Information No. 40, Comite Euro-International du Beton, Paris, 44-52.

Leonhardt, F. (1977). "Schub bei Stahlbeton und Spannbeton-Grundlagen der neueren Schubbemessung." Beton- und Stahlbetonbau, Berlin, Germany, 72(11), 270-277 (in German).

Leonhardt, F. (1977). "Schub bei Stahlbeton und Spannbeton-Grundlagen der neueren Schubbemessung." Beton- und Stahlbetonbau, $72(12), 295-392$ (Figs. 24-26).
Leonhardt, F., and Walther, R. (1962). "Beiträge zur Behandlung der Schubprobleme in Stahlbetonbau." Beton- und Stahlbetonbau, Berlin, Germany, 57(3), 54-64.

Leonhardt, R., and Walther, R. (1962). "Beiträge zur Behandlung der Schubprobleme in Stahlbetonbau." Beton- und Stahlbetonbau, Berlin, Germany, 57(6), 141-149 (in German)

Marti, P. (1980). "Zur plastischen Berechnung von Stahlbeton." Bericht $\mathrm{Nr}, 104$, Institute für Baustatik und Konstruktion, E.T.H. Zürich, Switzerland (in German).

Marti, P. (1985a). "Basic tools of reinforced concrete beam design." ACI $J ., 82(1), 46-56$

Mari, P. (185b). "Basic tools of reinforced concrete beam design." $A C I$ $J ., 82(1), 46-56$

Model Code 1990 (MC90). (1993). CEB-FIP, Thomas Telford, London, U.K.

Mörsch, E. (1922). Der Eisenbetonbau-Seine Theorie und Anwendung. (Reinforced concrete construction-Theory and application.) Wittwer, Stuttgart, Germany, 5th Ed., Vol. 1, Part 1 (1920) and Part 2 (1922).

Nielsen, M. P., and Braestrup, N. W. (1975). "Plastic shear strength of reinforced concrete beams." Tech. Rep. No. 3, Bygningsstatiske Meddelesler, Vol. 46.

Okamura, H., and Maekawa, K. (1994). "Experimental study of size effect in concrete structures." Size effect in concrete structures, $\mathrm{H}$. Mihashi, H. Okamura, and Z. P. Bažant, eds., E\&FN Spon, London, U.K., $3-24$.

Reineck, K.-H. (1991). "Model for structural concrete members without transverse reinforcement." Proc., IABSE Colloquium on Struct. Concrete, IABSE, Stuttgart, Germany, Rep. Vol. 62, 643-648.

Ritter, W. (1899). "Die Bauweise Hennebique." Schweizerische Bauzeitung, Zuirich, Switzerland, 33(7), 59-61.

Ruisch, H., Haugli, F. R., and Mayer, H. (1962). "Schubversuch an Stahlbeton-Rechteckbalken mit gleichmässing verteilter Belastung." Bull. No. 145, Deutscher Ausschuss für Stahlbeton, Berlin, Germany, 4-30 (in German).

Schlaich, J., Schafer, K., and Jannewein, M. (1987). "Toward a consistent design for structural concrete." $P C I J ., 32(3), 75-150$.

Shioya, Y., and Akiayama, H. (1994). "Application to design of size effect in reinforced concrete structures." Size effect in concrete structures, H. Mihashi, H. Okamura, and Z. P. Bažant, eds., E \& FN Spon, London, U.K., 409-416.

Shioya, T., Iguro, M., Nojiri, Y., Akiayama, H., and Okada, T. (1989). "Shear strength of large reinforced concrete beams." Fracture mechanics: Application to concrete, SP-118, Am. Concrete Inst., Detroit, Mich., 25-279.

Standard Specification for Design and Construction of Concrete Structures, Part I: Design. (1991). Japan Soc. of Civ. Engrs., Tokyo, Japan.

Talbot, A. N. (1909). "Tests of reinforced concrete beams-resistance to web stresses." Bull. 29, Univ. of Illinois Engrg. Experiment Station, Urbana, Ill.

Taylor, H. P. J. (1972). "Shear strength of large beams." J. Struct. Engrg., ASCE, 98(11), 2473-2490.

Thürlimann, B. (1976). "Shear strength of reinforced and prestressed concrete beams, CEB approach." Tech. Rep., E.T.H. Zürich, Switzerland.

Vecchio, F., and Collins, M. P. (1986). "The modified compression field theory for reinforced concrete elements subjected to shear." $A C I J$., $83(2), 219-231$

Wagner, H. (1929). "Ebene Blechwandträger mit sehr dünnem Stegblech." Zeitschrift für Flugtechnik und Motorluftschifffahr, Berlin, Germany, 20, 8-12 (in German)

Walraven, J. (1995). "Size effects: Their nature and their recognition in building codes." Studi e Ricerche, Politecnico di Milano, Italy, 16, $113-134$.

Walraven, J., and Lehwalter, N. (1994). "Size effects in short beams loaded in shear." ACI Struct. J., 91(5), 585-593.

Walraven, J. C. (1978). "The influence of depth on the shear strength of lightweight concrete beams without shear reinforcement." Stevin Lab. Rep. No. 5-78.4, Delft University of Technology, The Netherlands.

Withey, M. O. (1907). "Test of plain and reinforced concrete, series of 1906." Bull., Engrg. Ser., 4(1), Univ. of Wisconsin, Madison, Wisc., Nov., $1-66$.

Withey, M.O. (1908). "Tests of plain and reinforced concrete, series of 1907." Bull., Engrg. Ser., 4(2), Univ. of Wisconsin, Madison, Wisc., Nov., 1-66. 